In most patients thorough treatment with alkalies will suffice, provided it is accompanied by advice aimed at reducing reflux. $^{3}$ Weight reduction and attempts to improve general muscle tone should strengthen the oesophageal sphincter. Other details of diet need emphasizing, such as avoidance of fats, cutting down sugar, and limitation of tea and coffee drinking. Patients should be warned against stooping, sitting hunched up, especially after meals, and the tendency to slip down from a propped-up position in bed at night. Tight garments and straining, which cause undue rises in intraabdominal pressure, would be expected to put a strain on the sphincter. Smoking should be discouraged because it lowers sphincter pressure, ${ }^{4}$ probably by releasing $\beta$-adrenergic transmitters. So does atropine, and anticholinergic drugs should not be given.

A small number of patients will require additional drug treatment. Theoretically, cholinergic drugs should increase oesophageal motility and enhance sphincter tone, and a recent double-blind trial of oral bethanecol supports this. ${ }^{5}$ The drug was given to 20 patients with chronic heartburn in a dose of $25 \mathrm{mg}$ four times a day. There was considerable symptomatic improvement and the need for antacids was reduced in most patients during an eight months' period of observation. Metoclopramide, in a dose of $10 \mathrm{mg}$ three times a day, may be a useful alternative, though it acts differently by sensitizing oesophageal smooth muscle. A promising line for the future will be to explore the place of polypeptides. Analogues of prostaglandins, for example, might improve sphincter tone. These and other drugs should be evaluated by using physiological techniques for measuring the oesophageal response.

1 Misiewicz, J. J., Postgraduate Medical fournal, 1974, 50, 194.

2 Stanciu, C., and Bennett, J. R., Lancet, 1974, 1, 109.

3 Jones, F. A., Postgraduate Medical fournal, 1974, 50, 203.

4 Stanciu, C., and Bennett, J. R., British Medical fournal, 1972, 3, 793.

5 Farrell, R. L., et al., Annals of Internal Medicine, 1974, 80, 573.

\section{Lincomycin and Clindamycin Colitis}

Strangely, toxic effects of some antibiotics become recognized only after years of widespread use. Examples are those of chloramphenicol on the bone marrow, of tetracyclines on teeth, and of erythromycin estolate on the liver. To these must now be added another, an acute colitis following administration of lincomycin or its 7-chloro-7-deoxy derivative clindamycin. ${ }^{1-5}$ The clinical presentation is similar to an acute attack of ulcerative colitis, with diarrhoea which is often bloody, abdominal pain, and fever, the onset following the start of treatment after an interval of three to 25 days. Both oral and parenteral treatment with either drug can have this effect, though it usually follows oral treatment. Five of the seven cases reported by Scott et al. ${ }^{4}$ from New Zealand had undergone major surgery, but the three reported from Philadelphia by Manashil and Kern ${ }^{3}$ had been treated for only minor infections such as tonsillitis, and five of the seven cases described by Viteri et al. ${ }^{5}$ had been given the drug for upper respiratory tract disorders. Sigmoidoscopy typically showed an inflamed mucosa, with raised white plaques in many of the cases, an appearance typical of pseudomembranous colitis. In most of the cases rectal biopsy showed the features of this condition, with a membrane of fibrin, mucin, and inflammatory cells overlying the mucosa, which itself was sometimes necrotic and often contained dilated glands filled with mucus, and submucosal oedema and haemorrhage. In none was the histology indicative of ulcerative colitis and none had a history suggestive of this; in one patient sigmoidoscopic findings had been normal on a previous occasion. In many cases mucosal irregularities, mainly in the descending colon, were demonstrable by barium enema. Among reported cases there were seven deaths and an eighth patient required a total colectomy. Fortunately complete eventual recovery is the usual outcome. Though these antibiotics are known to affect the bowel flora, ${ }^{6}$ no changes to which colitis could be attributed have been shown by cultivation of the faeces.

Most cases of lincomycin and clindamycin colitis have recovered with only supportive and symptomatic therapy, but it seems wise to treat the condition with a course of systemic prednisolone, sulphasalazine, and local corticosteroid enemas, all of which have been used with apparent benefit. In the acute phase the antibiotic should be discontinued and the stool cultured, and the patient may need appropriate fluid and electrolyte replacement. Intensive intravenous therapy such as that used in acute ulcerative colitis ${ }^{7}$ may help tide severely ill patients over critical days, but emergency colectomy should be avoided if at all possible in view of the self-limiting nature of the condition. All patients should be followed up and investigated fully, when they have recovered clinically, to ensure that they are not suffering from a chronic form of colitis such as ulcerative colitis or Crohn's disease.

There is much that remains to be discovered about this condition. Its incidence is in dispute; according to the manufacturers $^{8}$ it is seen in no more than 1 in 100,000 treated cases, but were this so it is strange that Scott et al. ${ }^{4}$ should have encountered six cases in the seven months following the introduction of lincomycin on free prescription in New Zealand. Moreover, in a recent prospective study by Tedesco et al. ${ }^{9}$ of 200 consecutive patients given parenteral or oral clindamycin $21 \%$ developed diarrhoea and $10 \%$ a pseudomembranous colitis confirmed by proctoscopy but undergoing remission within a week when the drug was promptly stopped. Another question is how specific the lesions are. "Pseudomembranous" colitis has been described as resulting from treatment with other antibiotics, particularly tetracyclines and ampicillin, and indeed as occurring postoperatively years ago without the aid of any antibiotic. Are all these lesions indistinguishable? This is a proper subject for the most careful morbid anatomical study in any future cases. By what actual mechanism the mucosa is attacked remains a complete mystery, and might better be elucidated by animal experiment than by the study of patients, but no such experiments have yet been reported.

There remains the question of how far the use of these drugs should be restricted in view of the danger of this complication. A current pronouncement from the United States ${ }^{10}$ is as follows: "Clindamycin should be reserved for treatment of severe anaerobic infections. . . . that may be caused by Bacteroides fragilis, and for some staphylococcal infections in penicillin-allergic patients. Clindamycin should not be used for prophylaxis or for treatment of minor infections." This refers only to clindamycin, but since lincomycin can have the same effect and is preferable for no purpose to clindamycin, the same restriction should presumably apply to it. No one will dispute the imperative indication for clindamycin in serious Gram-negative anaerobic infections; most Bacteroides species are highly sensitive to it, more so than to lincomycin and much more so than to other antibiotics, and therapeutic results in these infections constitute a major advance. Both antibiotics have some special claim to consideration for treating staphylo- 
coccal osteomyelitis. Any other supposed indications seem to call for careful reconsideration. Some idea of the doubtful purposes for which lincomycin or clindamycin have been prescribed may be gained from published case histories of patients with this form of colitis. Indications mentioned include acne rosacea, "11 "a superficial skin infection,"12 "a mild upper respiratory infection,, 13 influenza, ${ }^{14}$ dental extraction, ${ }^{14}$ planting a pace-maker, ${ }^{2}$ and cover for operation on a metacarpophalangeal joint. ${ }^{2}$

\footnotetext{
1 Benner, E., and Tellman, W., American fournal of Gastroenterology, 1970, $54,214$.

2 Cohen, L. E., McNeill, C. J., and Wells, R. F., Fournal of the American Medical Association, 1973, 223, 1379.

3 Manashil, G. B., and Kern, J. A., American fournal of Gastroenterology, $1973,60,394$.

4 Scott, A. J., Nicholson, G. I., and Kerr, A. R., Lancet, 1973, 2, 1232.

5 Viteri, A. L., Howard, P. H., and Duck, W. P., Gastroenterology, 1974, 66, 1137.

6 Finegold, S. M., Harada, N. E., and Miller, L. G., Antibiotic Agents and Chemotherapy, 1965, 659 .

7 Truelove, S. C., and Jewell, D. P., Lancet, 1974, 1, 1067.

8 Hubbard, W. N., Jr., Lancet, 1974, 1, 172.

9 Tedesco, F. J., et al., Annals of Internal Medicine, in press.

10 The Medical Letter on Drugs and Therapeutics, 1974, 16, 73.

11 Wilkinson, S. P., Lancet, 1974, 1, 415.

12 Wise, R., Tudway, A. J. C., and Pelta, D. E., Lancet, 1974, 1, 878.

13 Dyck, W. P., Viteri, A. L., and Howard, P. H., Lancet, 1974, 1, 272.

14 Stroehlein, J. R., et al., Mayo Clinic Procecdings, 1974, 49, 240.
}

\section{Rebuilding Broken Bridges}

"Reorganisation-as social service departments already know and the N.H.S. will now be discovering-is a traumatic process." Many doctors will echo that down-to-earth sentiment, which sets the tone of a recently published report Social Work Support for the Health Service. ${ }^{1}$ Prepared by a departmental working party, the report is a constructive attempt to clear the air on a subject which has consistently raised the hackles of professional workers on both sides of the N.H.S./local government boundary.

One of the saddest episodes in recent Health Service history has been the sharp deterioration in relations between doctors and social workers that came in the wake of the Seebohm reforms. ${ }^{2}$ Patients' welfare can only have suffered as a result. Furthermore the search for a satisfactory solution has been made no easier by the dual reorganization of local government and the N.H.S. and, of course, worsening inflation. So, clearly the Government could not stand back in the hope that time would repair the broken bridges.

The Working Party on Collaboration, ${ }^{3}$ which proposed how the reorganized N.H.S. and the new local authorities could best co-operate, had looked carefully at the working relationship between social work departments and the Health Service. Its majority view was that social work support for health care should be the responsibility of local government. In accepting that advice, Sir Keith Joseph, then Secretary of State for Social Services, recognized it as controversial and so he accepted another suggestion in the collaboration report and set up a further working party (representative of all interests concerned) to study the practical aspects of the relationship.

With that background, this working party (chaired by Mr. G. J. Otton from the Department of Health) has exposed the misunderstandings between social workers and doctors, and acknowledged genuinely based criticisms. In such personal services as medicine and social work what really counts is co-operation at the level of the individual-among the patients, or clients as social workers describe them. Here doctors-especially general practitioners and psychiatristshave often been alarmed at the succession of young, inexperienced, non-specialist social workers who seemed to have replaced, for instance, an experienced local mental welfare officer with whom they had co-operated over the years. For their part social workers found the pressing demands of a general practitioner phoning about a problem case late in the afternoon difficult to fit in with the equally urgent needs of homeless families, the difficulties of running a new department, and the permanent shortage of resources. Like the N.H.S., social work is short of skilled people-a shortage aggravated by rapid promotion of experienced workers into an enlarged management structure. Admittedly, as the report points out, social work is at a much earlier stage in its development than the N.H.S. and training programmes are still being developed. But this shortage was well known and should have made the Seebohm proponents more cautious in planning the reorganization.

Nevertheless the new system has been imposed. In it one of the most hotly debated topics is the merits of the specialist versus the generic social worker. Doctors have greeted the generic social worker with little enthusiasm, laying blame for the new arrival on Seebohm. The authors of the present report, however, see "nothing in Seebohm to imply the wholesale abandonment of specialism in social work practice." If this interpretation is accepted by social work departments doctors will breathe a sigh of relief. But this controversy, though important to the N.H.S., is only part of a more far-reaching debate raging among social workers. Some accept the present social system and regard their job as helping their clients to cope with its defects. Others want a more radical approach. They favour social workers using their unique position in the community to initiate major social change.

"Continuing personal relationship" and regular "face-toface contact" among those responsible for patients/clients is urged in the report. In this way, it is rightly argued, "doctors learn to know that social work can contribute to patient care ... and social workers learn to carry out their work in a manner appropriate to the particular medical situation." In the present divided situation this truism bears repeating. Thus more personal contact is a recurring theme and the working party bluntly condemns "arrangements designed merely to establish that a social worker can be called in when necessary by impersonal communication from one system to another ... Equally commonsense advice is proffered on communications, teamwork, management, confidentiality, and the special problems of hospitals. In the interests of the community the health authorities and social work departments must co-operate-and not just in committees or by exchanging paper. It means social workers and doctors working together day by day. This report gives them good advice on how to rebuild their broken bridges.

1 Report of the Working Party on Social Work Support for the Health Service, London, H.M.S.O., 1974.

${ }^{2}$ Report of the Committee on the Local Authority and Allied Personal Social Services, Cmnd. 3703. London, H.M.S.O., 1968.

$3 A$ report from the Working Party on Collaboration botween the N.H.S. and Local Government on its activities to the end of 1972. London, H.M.S.O., 1973. 